\title{
UPAYA DAN PERAN KELUARGA DALAM MENJAGA KESELAMAATAN PASIEN DI RUANG RAWAT RUMAH SAKIT
}

\author{
Fanisa Nur Siregar \\ fanisanursiregar09@gmail.com
}

\begin{abstract}
Abstrak
Keselamatan pasien masih menjadi isu di berbagai pelayanan kesehatan di Indonesia. Keselamatan pasien adalah suatu sistem yang membuat asuhan keperawatan yang diberikan terhadap pasien menjadi lebih aman. Perawat merupakan salah satu sumber daya manusia yang sangat dibutuhkan untuk mencapai kinerja yang optimal. Kesalahan sering terjadi dalam memberikan pelayanan kesehatan kepada pasien di ruang rawat rumah sakit sehingga menyebabkan keselamatan pasein terganggu. Keluarga memiliki peran dalam menjaga keselamatan pasien selama di ruang rawat rumah sakit.
\end{abstract}

Kata kunci : keselamatan pasien, peran keluarga, rumah sakit

\section{LATAR BELAKANG}

Semua tindakan medis memiliki potensi resiko masing-masing. Terdapat banyaknya macam obat, jenis pemeriksaan dan tahapan prosedur, serta jumlah pasien dan staf Rumah Sakit yang cukup besar, merupakan hal yang potensial bagi terjadinya kesalahan medis. Kesalahan medis dapat menganggu keselamatan pasien di rumah sakit selama masa perawatan. Keselamatan pasien merupakan sebuah dasar dari sistem pelayanan kesehatan yang baik di berbagai tempat pelayanan kesehatan. Setiap tempat pelayanan kesehatan harus mengutamakan keselamatan pasien dalam menjalankan fungsinya. Rumah sakit adalah sebuah institusi pelayanan kesehatan yang menyelenggarakan pelayanan kesehatan perorangan secara paripurna yang menyediakan pelayanan rawat inap, rawat jalan dan gawat darurat. Rumah sakit merupakan sebuah institusi pemberi suatu pelayanan kesehatan yang bersifat kompleks. Sebagai pemberi layanan kesehatan, rumah sakit perlu melaksanakan keselamatan bagi dokter, perawat, tenaga kesehatan serta pasiennya. Rumah sakit wajib melaksanakan pelayanan kesehatan yang aman, 
bermutu, anti diskriminasi dan efektif, dengan mengutamakan kepentingan pasien. Rumah sakit wajib memenuhi hak pasien untuk memperoleh keamanan dan keselamatan selama menjalani perawatan di rumah sakit.

Mutu sebuah rumah sakit juga dapat di lihat dari tingkat keselamatan pasien yang di terapkan.Keselamatan pasien masih menjadi perbincangan dalam pelayanan kesehatan, khususnya di rumah sakit. Masih banyak kesalahan-kesalahan yang ditemukan dalam menerapkan keselamatan pasien di berbagai rumah sakit. Keselamatan pasien adalah pasien bebas dari cedera yang tidak seharusnya terjadi atau bebas dari cedera yang potensial akan terjadi kepada dirinya seperti: penyakit, cedera fisik/psikososial, cacat, kematian yang berhubungan dengan tindakan yang diberikan oleh pelayanan kesehatan.

Kelurga merupakan sebuah unit terkecil yang memiliki pengaruh terhadap kesehatan individu. Keluarga mempunyai peranan yang penting dalam menjaga keselamatan pasien. Seperti yang kita ketahui ada beberapa tugas keluarga yaitu menjaga dan merawat kondisi anggota keluarga agar tetap dalam keadaan optimal dan produktif, memperthankan dan meningkatkan status mental, mengantisipasi adanya perubahan social dan ekonomi, memotivasi dan memfasilitasi untuk memenuhi kebutuhan spiritual. Oleh karena itu, kelurga sangat berpengaruh sebagai sistem pendukung utama menjaga keselamatan keluarganya sebagai pasien di rumah sakit.

\section{METODE}

Metode yang digunakan dalam mendapatkan informasi dalam pembuatan jurnal ini adalah metode literature review yaitu metode dengan cara membaca dari berbagai sumber seperti jurnal online, skripsi, dan e-book serta membandingkan isi dari berbagai sumber yang dibaca dan menyimpulkan dalam hasil kajian yang di dapatkan pada jurnal, skripsi, e-book tentang upaya dan peran keluarga dalam menjaga keselamaatan pasien di ruang rawat rumah sakit. Dengan menggunakan sumber dengan terbitan paling tua tahun 2012.

\section{HASIL}

Keselamatan pasien bertujuan untuk menciptakan budaya keselamatan pasien di rumah sakit, meningkatkan akuntabilitas rumah sakit terhadap pasien dan masyarakat, menurunkan 
angka kejadian yang tidak diharapkan dan terlaksananya program-program pencegahan sehingga tidak terjadi pengulangan kejadian tidak diharapkan. Enam Sasaran Keselamatan Pasien terbagi menjadi 6 menurut Joint Commission International (JCI, 2017), adalah: pertama, mengidentifikasi pasien dengan tepat, kedua adalah meningkatkan komunikasi efektif yang singkat, akurat, lengkap, jelas dan mudah dimengerti oleh penerima pesan sehingga akan mengurangi kesalahan dan keselamatan pasien terjaga, ketiga adalah meningkatkan keamanan obat-obat risiko tinggi. Sasaran diperlukan pengawasan yang tinggi terhadap pemakaian obat yang diperlukan. Kemudian sasaran keempat adalah memastikan keamanan operasi,pasien dan keluarga diberikan informasi prosedur tindakan pembedahan serta diminta persetujuan secara tertulis atau inform consent. Sasaran kelima yaitu mengurangi risiko infeksi akibat perawatan kesehatan, disini Semua petugas kesehatan melaksanakan kebersihan tangan(hand hygiene) enam langkah sesuai standar WHO, Petugas kesehatan membersihkan tangan pada 5 kondisi (moment) yaitu sebelum kontak dengan pasien. Yang terakhir yaitu mengurangi risiko cedera pasien akibat jatuh. Pelaksanaannya dengan melakukan pengkajian pasien risiko jatuh.

Pasien yang dirawat di rumah sakit merupakan individu yang sedang memiliki masalah dalam kesehatan, sehingga dimungkinkan mengalami kesulitan untuk memenuhi kebutuhan sendiri termasuk menjaga keselamatan diri sendiri, oleh sebab itu pasien membutuhkan dukungan dari keluarga dan tim kesehatan yang merawat. Peran keluarga secara aktif dalam menjaga keselamatan pasien rawat inap adalah :

1. Memberikan informasi yang benar, jelas, lengkap dan jujur

2. Mengetahui dan melaksanakan kewajiban serta tanggung jawab pasien maupun keluarga.

3. Mengajukan pertanyaan-pertanyaan untuk hal yang tidak dimengerti.

4. Memahami dan menerima konsekuensi pelayanan.

5. Mematuhi dan menghormati peraturan rumah sakit.

6. Memperlihatkan sikap menghormati dan tenggang rasa dalam proses bersama tim kesehatan mengelola pasien.

7. Memenuhi kewajiban finansial yang disepakati. 


\section{PEMBAHASAN}

Berbicara tentang keselamatan pasien, maka selalu identik dan dikaitkan dengan fasilitas kesehatan yang merupakan sarana prasarana terjadinya pelayanan kesehatan. Salah satu fasilitas pelayanan kesehatan yang paling besar adalah rumah sakit. Rumah sakit merupakan sebuah institusi pemberi suatu pelayanan kesehatan yang bersifat kompleks. Sebagai pemberi layanan kesehatan, rumah sakit perlu melaksanakan keselamatan bagi dokter, perawat, tenaga kesehatan serta pasiennya. Sebuah rumah sakit wajib melaksanakan pelayanan kesehatannya yang aman, berkualitas, anti diskriminasi dan efektif, dengan mengutamakan kepentingan- kepentingan pasien. Rumah sakit harus memenuhi hak pasien untuk memperoleh keamanan dan keselamatan selama menjalani perawatan di rumah sakit.

Ruang rawat merupakan tempat dimana pasien dirawat selama masa pemulihan kesehatannnya dengan jangka waktu tertentu sesuai keadaannya. Di ruang rawat adalah tempat pasien menghabiskan waktunya untuk pemulihan kesehatan. Oleh karena itu di ruang rawat banyak muncul kejadian yang tidak Diinginkan (KTD) yang dapat mengancam keselamatan pasien. Kemungkinan terjadinya kejadian tidak diharapkan dapat diakibatkan oleh berbagai macam kegiatan yang dilakukan oleh berbagai macam profesi di rumah sakit. Sebagai contoh adalah kesalahan dalam memberi diagnosis, kejadian kesalahan tes laboratorium, kesalahan pemberian obat, kesalahan pada sistem komunikasi.

Mutu sebuah rumah sakit juga dapat di lihat dari tingkat keselamatan pasien yang di terapkan. Keselamatan pasien (Patient Safety) adalah suatu prosedur atau proses dalam suatu rumah sakit yang memberikan pelayanan pasien yang lebih aman. Terdapat lima isu penting yang berkaitan dengan keselamatan di rumah sakit yaitu: keselamatan pasien (patient safety), keselamatan pekerja atau petugas kesehatan, keselamatan bangunan dan peralatan di rumah sakit, keselamatan lingkungan dan keselamatan bisnis rumah sakit. Keselamatan Pasien merupakan suatu sistem dimana rumah sakit memberikan asuhan pasien agar lebih aman, mencegah terjadinya cidera yang disebabkan oleh kesalahan akibat melaksanakan suatu tindakan atau tidak mengambil tindakan yang seharusnya diambil.

Tujuan dari pelaksanaan keselamatan pasien menurut Joint Commission International (JCI, 2017) yaitu: 
1) Meningkatkan ketepatan pada identifikasi pasien. yaitu dengan menggunakan 2 identitas pasien yang utama adalah nama dan tanggal lahir pasien, untuk mengidentifikasi dan meminimalisir kesalahan yang mungkin terjadi.

2) Meningkatkan komunikasi terapeutik pada seluruh pemberi pelayanan kesehatan di rumah sakit dengan menggunakan teknik Situation, Background, Assessment dan Recommendation (SBAR) dalam melaporkan kondisi kritis maupun ketika timbang terima pasien.

3) Meningkatkan ketepatan dalam managemen obat, di antaranya dengan cara memberikan label atau tanda pada obat.

4) Menurunkan risiko infeksi melalui kegiatan membersihkan tangan dengan benar dan menjaga rantai penyebaran infeksi melalui darah serta mencegah resistensi penggunaan obat infeksi.

5) Menggunakan program pengobatan selama perawatan secara tepat dan akurat, menginfokan pemberian obat secara lengkap dan berkesinambungan dengan petugas berikutnya, daftar pengobatan pasien dibuat lengkap, diupayakan pasien mendapatkan obat.

6) Mencegah pasien dari kemungkinan kejadian risiko jatuh di ruangan.

7) Mengurangi risiko pasien terjadi dekubitus (cedera tekan).

8) Rumah sakit mengidentifikasi keselamatan pasien.

9) Standar umum menghindari kesalahan lokasi, prosedur dan pasien pada ketika tindakan operasi berjalan dalam masa perawatan.

\section{a. Peran keluarga secara umum}

Keluarga merupakan orang yang banyak menghabiskan waktu di ruang rawat rumah sakit untuk menjaga pasien. Oleh karena itu keluarga memeiliki peran dalam menjaga keselamatan klien di ruang rawat. Keluarga juga memberikan dampak dalam meningkatkan keselamatan pasien, seperti menemani pasien berjalan ke kamar mandi dan memantau keadaan pasien untuk melaporkannya kepada perawat. Dalam melaksanakan program tersebut diperlukan kerja sama antara tim kesehatan serta pasien dan keluarga. Peran keluarga secara aktif dalam menjaga keselamatan pasien di rawat inap adalah : 
1. Memberikan informasi yang benar, jelas, lengkap dan jujur. Maksudnya disini adalah keluarga harus memberikan informasi yang sebenarnya tanpa ada yang di tutupi. Tindakan ini dapat mengurangi kesalahan perawat maupun tenaga kesehatan dalam memberikan pelayanan terhadap pasien

2. Mengetahui dan melaksanakan kewajiban serta tanggung jawab pasien maupun keluarga. Tindakan ini diharapkan dapat mengurangi angka kejadian yang tidak diinginkan di ruang rawat. Kewajiban keluarga adalah memberi informasi kepada perawat apa yang terjadi kepada pasien setelah di berikan tindakan.

3. Mengajukan pertanyaan-pertanyaan untuk hal yang tidak dimengerti. Ini berkaitan dengan hal apa yang bisa dilakukan keluarga kepada pasien agar tidak terjadi tindakan yang membahayakan pasien. Contohnya pasien tidak boleh diberi makanan yang berminyak, tetapi karna tidak menanyakan hal ini ke perawat maka terjadi gangguan kepada pasien.

4. Memahami dan menerima konsekuensi pelayanan.

5. Mematuhi dan menghormati peraturan rumah sakit. Ini bermakna bahwa keluarga harus mengikuti peraturan yang ada di rumah sakit. Seperti selalu mencuci tangan dengan handrub sebelum maupun sesudah menyentuh pasien.

6. Memperlihatkan sikap menghormati dan tenggang rasa dalam proses bersama tim kesehatan mengelola pasien

7. Memenuhi kewajiban finansial yang disepakati.

\section{b. Penerapan enam sasaran keselamatan pasien dan peran keluarga dalam menjaga keselamatan pasien rawat inap di rumah sakit}

\section{Ketepatan Identifikasi Pasien,}

Identifikasi pasien merupakan hal utama yang penting dalam pemberian pelayanankesehatan kepada pasien. Pasien yang memiliki resiko dalam ketidaktepatan identifikasi adalah pasien dalam keadaan tidak sadar, gelisah, mengalami gangguan penglihatan, gangguan pendengaran, gangguan proses pikir, mendapat obat bius, atau gangguan lain, serta pasien yang pindah ruang rawat atau bertukar tempat tidur saat perawatan. Identifitas pasien dalam masa perawatan dengan menggunakan dua identitas pasien, nama pasien, waktu 
kelahirannya, nama ruang perawatan tidak boleh dipakai sebagai identitas pasien. Maka peran pasien dan keluarga untuk memastikan ketepatan identifikasi pasien adalah:

a. Memberikan data diri yang tepat dan lengakp pada saat pertama mendaftar sesuai dokumen data diri yang dimiliki. Data yang utama dibutuhkan adalah nama dan tanggal lahir pasien

b. Selama rawat inap pasien memakai gelang. Pasien dan keluarga harus memahami fungsi gelang dan patuh untuk menggunakan gelang tersebut selama rawat inap karena gelang tersebut dipakai oleh tenaga kesehatan guna memastikan kebenaran identitas dan faktor risiko pasien saat memberikan pelayanan. Biasanya gelang warna biru untuk laki-laki dan gelang warna merah muda untuk perempuan,gelang warna merah dipasangkan pada pasien yang memiliki riwayat alergi, serta gelang warna kuning dipasangkan pada pasien yang memiliki risiko jatuh

c. Pasien atau keluarga dapat bekerjasama saat dilakukan verifikasi identitas oleh petugas saat akan melakukan tindakan, memberikan obat, mengambil preparat untuk pemeriksaan laborat dan lain-lain.

\section{Komunikasi efektif}

Identifitas pasien dilakukan dengan menggunakan dua identitas pasien, nama pasien, waktu kelahirannya, ruang perawatan tidak boleh dipakai untuk identitas pasien. Komunikasi terapeutik adalah komunikasi efektif yang dapat dilakukan. Peran pasien dan keluarga mewujudkan komunikasi efektif adalah:

a. Menetapkan anggota keluarga yang diberi tugas untuk berkomunikasi dengan tenaga kesehatan. Penunjukkan ini diperlukan untuk memastikan komunikasi berlangsung efektif, tidak mengalami rantai komunikasi yang panjang dan kompleks yang berisiko menyebabkan perubahan makna dari informasi.

b. Memberikan informasi dan data terkait kondisi pasien kepada perawat dengan benar dan jelas.

c. Memberikan informasi pada petugas bila ada kejadian tidak diharapkan.

d. Meminta informasi yang diperlukan kepada tenaga kesehatan 


\section{Meningkatkan keamanan Obat-obatan risiko tinggi}

Peningkatan obat yang perlu diwaspadasi adalah usaha yang paling efektif untuk mengurangi kesalahan yang mengganggu keselamatan pasien akibat pemberian obat dengan berfokus bagaimana mempersiapkan, menyimpan, obat injeksi Peran serta keluarga dalam menjamin keamanan pemberian obat adalah

a) Memberikan informasi yang lengkap tentang riwayat obat yang pernah dikonsumsi sebelum masuk rumah sakit

b) Memberikan informasi tentang riwayat alergi yang dimiliki pasien saat menggunakan obat tertentu

c) Mendukung pengawasan pemberian obat selama rawat inap dengan cara memastikan identitas pasien benar, menanyakan jenis obat yang diberikan, tujuan pemberian, dosis dan waktu pemberian obat

\section{Memastikan keamanan operasi.}

Tindakan operasi merupakan salah satu prosedur yang mungkin dilakukan pada pasien untuk mengatasi masalah kesehatannya. Hal yang paling penting dilakukan adalah tepat-lokasi, tepat-prosedur, tepat-pasien. Salah satu prosedur yang dilakukan sebelum tindakan operasi adalah proses verifikasi. Peran pasien dan keluarga dalam proses verifikasi sebelum operasi adalah memberi informasi yang benar dan bekerja sama secara kooperatif. Proses yang dilakukan yaitu :

- Verifikasi lokasi, prosedur, dan pasien yang benar Proses ini dilakukan dengan membuat tanda pada lokasi yang dioperasi. Penandaan lokasi operasi ini melibatkan pasien, dibuat oleh dokter yang akan melakukan tindakan dan dilaksanakan saat pasien dalam keadaan sadar .Tanda ini tidak boleh dihapus dan harus terlihat sampai saat akan disayat.

- Memastikan bahwa semua dokumen, foto (imaging), hasil pemeriksaan yang relevan tersedia, diberi label dengan baik

- Melakukan verifikasi ketersediaan peralatan khusus yang dibutuhkan 


\section{Mengurangi risiko infeksi akibat perawatan kesehatan}

Rumah sakit merupakan tempat berkumpulnya berbagai jenis kumandan penyakit. Pasien yang sedang dirawat memiliki daya tahan tubuh yang tergolong rendah dengan demikian di butuhkan suatu proses untuk mencegah timbulnya infeksi terhadap pasien baik dari perawat maupun keluarga. Peran pasien dan keluarga dalam pengurangan risiko terkait pelayanan kesehatan adalah :

- Menerapkan prosedur cuci tangan yang benar.

- Membatasi pengunjung pasien

- Menerapkan etika batuk yang benar

\section{Mengurangi risiko cedera pasien akibat jatuh}

Jatuh merupakan kejadian seseorang mengalami kontak dengan lantai atau dataran yang lebih tinggi tanpa sengaja. Kejadian pasien terjatuh dapat menjadi penyebab kematian, oleh sebab itu layanan kesehatan harus menjaga pasien tidak jatuh, melakukan analisis pasien risiko terjatuh. Rumah sakit mengambil tindakan untuk mengurangi risiko dengan melakukan pengkajian faktor-faktor yang dapat menyebabkan jatuh seperti, penggunaan obat, gaya jalan dan keseimbangan, alat bantu berjalan yang digunakan oleh pasien, riwayat jatuh saat berjalan atau saat istirahat baring di tempat tidur.

\section{PENUTUP}

Keselamatan pasien sangat penting untuk meeningkatkan mutu pelayanan kesehatan di rumah sakit. Dalam menjaga keselamatan pasien bukan hanya tanggung jawab perawat dalam memberi asuhan keperawatan, tetapi juga menjadi tanggung jawab keluarga. Keluarga memiliki peranan penting dalam menjaga keselamatan pasien di ruang rawat rumah sakit untuk menghindari kejadian yang tidak di inginkan selama pasien menjalani masa perawatan. Keluarga adalah orang yang menghabiskan waktu 24 jam dengan pasien selama masa perawatan. Keluarga juga mengontrol perkembangan pasien. 


\section{DAFTAR PUSTAKA}

Abubakar, N., \& Nilamsari, N. (2017). PENGETAHUAN DAN SIKAP KELUARGA PASIEN RAWAT INAP RUMAH SAKIT HAJI SURABAYA TERHADAP PENCEGAHAN INFEKSI NOSOKOMIAL . JURNAL MANAJEMEN KESEHATAN Yayasan RS. Dr. Soetomo, Volume 3, No. 1, 49-61.

Harus, B. D., \& dkk. (2015). PENGETAHUAN PERAWAT TENTANG KESELAMATAN PASIEN DENGAN PELAKSANAAN PROSEDUR KESELAMATAN PASIEN RUMAH SAKIT (KPRS) DI RUMAH SAKIT PANTI WALUYA SAWAHAN MALANG . Jurnal CARE, Vol. 3, No. 1, 25-32.

Kamil, H. (2018). Patient Safety. Idea Nursing Journal. 1(1)., 1-8.

Kertapati, Y. (2019). Tugas Kesehatan Keluarga dan Tingkat Kemandirian Keluarga di Wilayah Pesisir Kota Surabaya. Jurnal Ilmiah Keperawatan Stikes Hang Tuah Surabaya. 14 (1), 1-8.

Lombogia, A., \& dkk. (2016). HUBUNGAN PERILAKU DENGAN KEMAMPUAN PERAWAT DALAM MELAKSANAKAN KESELAMATAN PASIEN (PATIENT SAFETY) DI RUANG AKUT INSTALASI GAWAT DARURAT RSUP PROF. DR. R. D. KANDOU MANADO. e-journal Keperawatan (e-Kp) Volume 4 Nomor 2, 1-8.

Najihah. (2018). BUDAYA KESELAMATAN PASIEN DAN INSIDEN KESELAMATAN PASIEN DI RUMAH SAKIT: LITERATURE REVIEW. JOURNAL OF ISLAMIC Volume 3 Nomor 1, 1-8.

Rivai , F., \& dkk. (2016). FAKTOR YANG BERHUBUNGAN DENGAN IMPLEMENTASI KESELAMATAN PASIEN DI RSUD AJJAPPANNGE SOPPENG TAHUN 2015. JURNAL KEBIJAKAN KESEHATAN INDONESIA VOLUME 05 No. 04, 152-157.

Simamora, R. H. (2019). Buku ajar pelaksanaan identifikasi pasien. Uwais Inspirasi Indonesia.

Sriningsih, N., \& Marlina, E. (2020). PENGETAHUAN PENERAPAN KESELAMATAN PASIEN (PATIENT SAFETY) PADA PETUGAS KESEHATAN. Jurnal Kesehatan, Vol. 9 No. 1. 
Widisari. (2018). Hubungan Penerapan keselamatan Paisen dengaan kepuasan Pasien di Rumah sakit.Tesis. Tidak Diterbitkan. Fakultas Ilmu Keperawatan Universitas Indonesia.

Yusuf, M. (2017). Penerapan Patient Safety Di Ruang Rawat Inap Rumah Sakit Umum Daerah Dr. Zainoel Abidin. Jurnal Ilmu Keperawatan Vol 5 No1 , 85-89. 